\title{
Finite Element Analysis of the Enhanced Strength of Laterally Restrained RC Slabs
}

\author{
Ahmed Shaat ${ }^{1, *}$, Susan Taylor ${ }^{2}$, Desmond Robinson ${ }^{2}$, Barry Rankin², David Cleland ${ }^{2}$ \\ ${ }^{1} \mathrm{MZ}$ and Partners Architectural and Engineering Consultancy, P.O.Box: 5281, Doha, Qatar \\ ${ }^{2}$ School of Planning, Architecture and Civil Engineering, Queen's University Belfast, Belfast, BT9 5AD, UK \\ *Corresponding Author: ashaath2002@yahoo.com
}

Copyright $(2014$ Horizon Research Publishing All rights reserved.

\begin{abstract}
This paper presents the numerical simulation of the ultimate behaviour of 85 one-way and two-way spanning laterally restrained concrete slabs of variable thickness, span, reinforcement ratio, strength and boundary conditions reported in literature by different authors. The developed numerical model was described and all the assumptions were illustrated. ABAQUS, a Finite Element Analysis suite of software, was employed. Non-linear implicit static general analysis method offered by ABAQUS was used. Other analysis methods were also discussed in general in terms of application such as Explicit Dynamic Analysis and Riks method. The aim is to demonstrate the ability and efficacy of FEA to simulate the ultimate load behaviour of slabs considering different material properties and boundary conditions. The authors intended to present a numerical model that provides consistent predictions of the ultimate behaviour of laterally restrained slabs that could be used as an alternative for expensive real life testing as well as for the design and assessment of new and existing structures respectively. The enhanced strength of laterally-restrained slabs compared with conventional design methods predictions is believed to be due to compressive membrane action (CMA). CMA is an inherent phenomenon of laterally restrained concrete beams/slabs. The numerical predictions obtained from the developed model were in good correlation with the experimental results and with those obtained from the CMA method developed at the Queen's University Belfast, UK.
\end{abstract}

Keywords Bridges, Buildings, Structures and Design, Concrete Structures, Slabs and Plates

\section{Introduction}

It has been recognised for some time that laterally restrained slabs exhibit strengths in excess of those estimated by standard flexural and shear design methods $[1,2]$. Lateral restraint prevents or reduces in-plane displacement of the slab boundaries which causes arching forces to develop within the slab, thereby increasing the ultimate load capacity of the slab. Supporting beams and/or other surrounding parts of the structure can provide the necessary lateral restraint. This phenomenon is known as Arching Action or Compressive Membrane Action (CMA), [3]. The consideration of CMA in design can lead to substantially reduced quantities of bending reinforcement, and therefore provides advantages in terms of economy, durability and sustainability where CMA can be employed in the assessment of the strength of existing structures such as bridges resulting in a capacity considerably in excess of the original design strength based on codes [4].

The main objective of this paper is to demonstrate the ability and efficacy of FEA to simulate the ultimate load behaviour of slabs, including CMA, using ABAQUS FEA (a Finite Element Analysis suite of software, [5]) considering different boundary conditions, concrete strengths, span to depth ratios and reinforcement percentages. Non-linear numerical simulations using explicit dynamic and implicit static methods are also discussed in general. It is the intention of the authors to present a non-linear numerical model that provides a consistent prediction of the ultimate behaviour of laterally restrained slabs that, in future, could be used as a substitute for expensive real life testing and for the design and assessment of new and existing structures respectively. The numerical model was used to predict the ultimate capacities of 42 one-way spanning slab specimens and 43 two-way spanning slab specimens with good success.

The experimental and FEA results were also compared with the CMA prediction methods developed at the Queen's University Belfast [6-8] which are discussed in the following section.

\section{CMA Theory Developed at Queen's University Belfast}

The development of prediction methods incorporating Compressive Membrane Action at Queens University Belfast began in the early 1980's. Rankin [6,7] developed a 
theory for arching action in slab strips and integrated this into his method for predicting punching failure in conventional unrestrained slabs to form an integrated approach to predicting the enhanced punching strength of laterally restrained slabs. Following this approach, Kirkpatrick, Rankin and Long [9] examined the enhancement due to CMA in bridge decks and produced a method for predicting the enhanced punching strength of bridge deck slabs. After full scale testing of a bridge, Kirkpatrick et al [10] concluded that CMA also enhances the serviceability of bridge deck slabs and can be utilized in the assessment of existing concrete bridge decks. Later, Long, Kirkpatrick and Rankin [11] stated that there was considerable potential for the development of highly durable deck slabs, without conventional reinforcement, where the boundary conditions allow CMA to develop. In a further paper, Rankin and Long [12] presented full details of their method for predicting the enhanced ultimate load capacity of laterally restrained slabs strips. The method was based on deformation theory and utilized an elastic-plastic stress-strain criterion for concrete. The loads carried by bending and arching action were calculated separately and then added to give the total ultimate load capacity. A simple equivalent strip approach, based on a three-hinged arch analogy, allowed for the actual degree of lateral restraint, see Figure 1. The method of prediction was validated by correlation with a wide range of test results from various sources. The findings of the research into CMA at Queen's University Belfast up to this time were incorporated into the United Kingdom design manual for roads and bridges [13], 'BD 81/02 - Use of Compressive Membrane Action in Bridge Decks'.
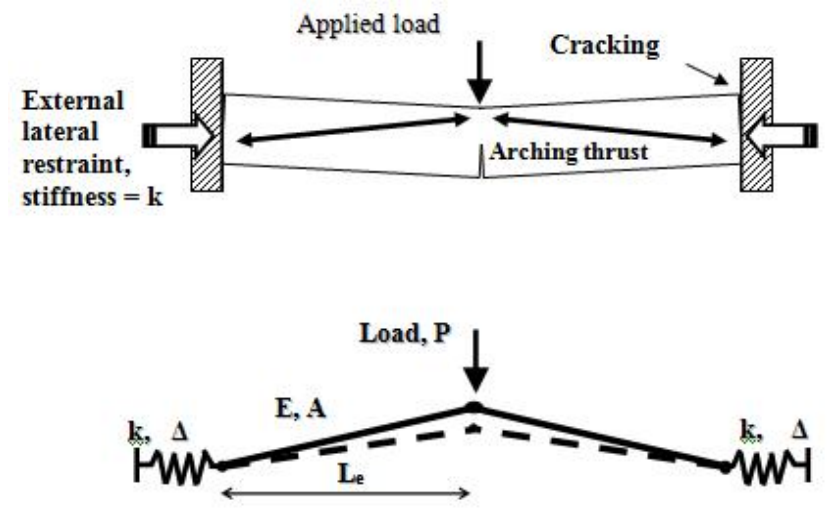

Figure 1. Arching action and three-hinged arch analogy

Following on from this research, Taylor, Rankin and Cleland [14] presented the results of laboratory tests on 15 reinforced concrete slab strips, typical of a bridge deck slab, and compared them to predicted strengths using the current codes and CMA theory. The tests showed that the strength of laterally restrained slabs was sensitive to both the degree of external lateral restraint and the concrete compressive strength. Taylor, Rankin and Cleland [14] presented a relationship for the plastic strain value of high strength concrete. Taylor, Rankin and Cleland used this relationship in conjunction with Rankin and Long's [12] method to predict the strength of laterally restrained slab strips with concrete cube compressive strengths up to $100 \mathrm{~N} / \mathrm{mm}^{2}$. They thereby promoted more economical and durable bridge deck construction by utilizing the benefits of high strength concrete. Shaat [15] subsequently developed the method further by introducing a rational method for calculating the lateral restraint stiffness of surrounding slab restraint configurations in two-way slab systems utilising the axial and bending stiffness's of the surrounding slabs.

\section{Numerical Simulation of One-way and Two-way Spanning Slabs}

This paper concentrates on the numerical simulation of one-way spanning slab strips tested by Roberts [16], Birke [17] and Taylor [14] and two-way spanning slabs tested by Rankin [6]. These have been selected because of the variation in concrete compressive strength, span to depth ratio, reinforcement ratio, boundary condition and lateral restraint stiffness.

\subsection{Tests by Roberts}

The experimental models of Roberts [16] consisted of 17 slab strips, $229 \mathrm{~mm}$ in width and $1461 \mathrm{~mm}$ in length (span). Load was applied uniformly at 4-points along the span. Two groups of strips were tested $-76 \mathrm{~mm}$ and $51 \mathrm{~mm}$ deep. The concrete cylinder compressive strength varied between 14.5 $\mathrm{N} / \mathrm{mm}^{2}$ and $45 \mathrm{~N} / \mathrm{mm}^{2}$ (based on cylinder strength $=0.8 \mathrm{x}$ cube strength). Annealed mild steel reinforcement, $4.8 \mathrm{~mm}$ in diameter with a definite yield point, was used as bottom reinforcement for all the specimens. The reinforcement percentage varied from 0.231 to 0.926 . To provide lateral restraint, a large reinforced high strength concrete surrounding frame was cast. The lateral restraint stiffness per unit width was estimated by Roberts as $22.7 \mathrm{kN} / \mathrm{mm}^{2}$ for all the tests. The strips to be tested were inserted into the concrete surround, refer to Figure 2(a) and Table 1 for further information on the test configuration.

\subsection{Tests by Birke}

The Series 1 experimental models of Birke [17] consisted of 10 groups of slab strips (beams), $50 \mathrm{~mm}$ in width and $200 \mathrm{~mm}$ in length (span), as shown in Table 2. Each specimen presented in the table is the average of two similar specimens except for the $10.7 \mathrm{~mm}$ thick specimen as it was the average of 10 similar specimens. Load was applied at mid-span. Depths of $10.7 \mathrm{~mm}$ up to $50 \mathrm{~mm}$ were investigated. The concrete compressive cylinder strength varied between 26.9 $\mathrm{N} / \mathrm{mm}^{2}$ and $44.8 \mathrm{~N} / \mathrm{mm}^{2}$ based on cylinder strength $=1.2 \mathrm{x}$ cube strength as was experimentally confirmed by Birke [17]. This unusual ratio of cylinder to cube strength was due to the large scale factor involved with the specimens and was substantiated by tests on concentrically loaded prisms reported by Birke in his paper. No reinforcement was 
provided in these test specimens. To provide lateral restraint, the specimens were confined by a very stiff surround; refer to Figure 2(b) and Table 2 for further information and details.

\subsection{Tests by Taylor}

The experimental models of Taylor [14] consisted of 15 slab strips, $475 \mathrm{~mm}$ in width and $1415 \mathrm{~mm}$ in length (span) and $150 \mathrm{~mm}$ in thickness. Load was applied at mid-span except for one specimen where load was applied at $1 / 4$ span points. The concrete compressive cylinder strength varied between $25 \mathrm{~N} / \mathrm{mm}^{2}$ and $80.9 \mathrm{~N} / \mathrm{mm}^{2}$ (based on cylinder strength $=0.8 \times$ cube strength). Reinforcement percentages used were $0.687 \%$ Top and Bottom, $0.953 \%$ at mid-depth and one specimen had no reinforcement. Three types of lateral restraint arrangement were provided resulting in lateral restraint stiffnesses of zero stiffness, $197 \mathrm{kN} / \mathrm{mm}^{2}$ and $410 \mathrm{kN} / \mathrm{mm}^{2}$. In addition to variation in lateral restraint stiffness, some specimens were fully fixed at the ends and others were simply supported. Refer to Figure 2(c) and Table 3 for more details on the test information and general arrangement.

\subsection{Tests by Rankin}

Two series of $1 / 4$ scale tests were carried out by Rankin [6]. Both series were designed to represent a typical flat slab-column configuration of $6.4 \mathrm{~m}$ span and $400 \mathrm{~mm}$ square column size, at full scale. The first series was 27 specimens of square contraflexure models of size $700 \mathrm{~mm} \times 700 \mathrm{~mm}$. The second series was 16 larger square specimens ranging in sizes from $800 \mathrm{~mm} \times 800 \mathrm{~mm}$ up to $1600 \mathrm{~mm} \times 1600 \mathrm{~mm}$. All of the slabs were supported on a square steel rig spanning $640 \mathrm{~mm}$ which represented the length to the assumed line of contraflexure at $0.4 \mathrm{~L}$, where $\mathrm{L}$ is the span between centres of adjacent slab bays (assumed to be $6400 / 4=1600 \mathrm{~mm}$ at $1 / 4$ scale). Refer to Figure 2(d) and Tables 4 and 5 for test information and configuration. A concentrated load was applied through a column stub at the centre of the slab models. The concrete compressive cylinder strength varied between $26.8 \mathrm{~N} / \mathrm{mm}^{2}$ and $43 \mathrm{~N} / \mathrm{mm}^{2}$ (based on cylinder strength $=0.8 \times$ cube strength). Different reinforcement percentages and slab thicknesses were investigated. Rankin assumed that the region of slab outside the support lines contributed to the lateral stiffness and enhanced the slab capacity.

\section{The Non-Linear Finite Element Analysis Numerical Model}

The ABAQUS finite element analysis suite of software [5] was used to simulate the non-linear behaviour of the slab specimens up to failure simulating the hardening and softening regimes of the concrete material. Standard implicit static or explicit dynamic nonlinear analyses could generally be used for this purpose. However, this paper generally discusses the explicit dynamic nonlinear analysis and compares the use of the implicit static general method to the implicit static Riks method.

The following paragraphs describe the different associated parameters that were adopted for the purpose of this investigation for all of the $85 \mathrm{slab}$ specimens analyzed. These parameters were effectively unchanged to ensure uniformity of the comparison with the predicted experimental results. Further details on ABAQUS can be obtained from the ABAQUS theory and analysis manuals $[18,19]$. 
Table 1. Comparison between the experimental and predicted failure loads of Robert's [16] specimens

\begin{tabular}{|c|c|c|c|c|c|c|c|c|c|c|c|c|c|}
\hline STRIP & d & $\mathrm{h}$ & $\mathrm{f}_{\mathrm{cu}}$ & $\rho$ & $f_{y}$ & k & $\mathrm{P}_{\mathrm{T}}$ & $\mathrm{P}_{\mathrm{b}}$ & $\mathrm{P}_{\mathrm{T}}$ & $\mathrm{P}_{\mathrm{Q}}$ & $\mathrm{P}_{\mathrm{T}}$ & $\mathrm{P}_{\mathrm{FEA}}$ & $\mathrm{P}_{\mathrm{T}}$ \\
\hline NO. & $\mathrm{mm}$ & $\mathrm{mm}$ & $\mathrm{N} / \mathrm{mm}^{2}$ & $\%$ & $\mathrm{~N} / \mathrm{mm}^{2}$ & $\mathrm{kN} / \mathrm{mm}^{2}$ & $\mathrm{kN}$ & $\mathrm{kN}$ & $/ \mathrm{P}_{\mathrm{b}}$ & $\mathrm{kN}$ & $/ \mathrm{P}_{\mathrm{Q}}$ & $\mathrm{kN}$ & $/ \mathrm{P}_{\mathrm{FEA}}$ \\
\hline $\mathrm{RB} 10$ & 42.6 & 51 & 50.4 & 0.556 & 241 & 22.7 & 18.72 & 3.05 & 6.14 & 15.16 & 1.23 & 17.21 & 1.09 \\
\hline RB11 & 42.6 & 51 & 24.7 & 0.556 & 241 & 22.7 & 11.86 & 2.98 & 3.98 & 10.79 & 1.10 & 10.61 & 1.12 \\
\hline $\mathrm{RB} 12$ & 42.6 & 51 & 32.8 & 0.741 & 241 & 22.7 & 16.22 & 3.98 & 4.08 & 13.00 & 1.25 & 13.36 & 1.21 \\
\hline RB13 & 42.6 & 51 & 30.2 & 0.741 & 241 & 22.7 & 13.14 & 3.96 & 3.32 & 12.48 & 1.05 & 12.62 & 1.04 \\
\hline RB14 & 42.6 & 51 & 49.7 & 0.741 & 241 & 22.7 & 18.5 & 4.03 & 4.59 & 15.62 & 1.18 & 17.56 & 1.05 \\
\hline $\mathrm{RB} 15$ & 42.6 & 51 & 24.1 & 0.926 & 241 & 22.7 & 13.96 & 4.82 & 2.90 & 11.55 & 1.21 & 11.41 & 1.22 \\
\hline RB17 & 42.6 & 51 & 53.3 & 0.926 & 241 & 22.7 & 16.88 & 5.02 & 3.36 & 16.61 & 1.02 & 18.04 & 0.94 \\
\hline RB18 & 68.3 & 76 & 27 & 0.578 & 241 & 22.7 & 36.7 & 7.99 & 4.59 & 30.4 & 1.21 & 30.91 & 1.19 \\
\hline RB19 & 68.3 & 76 & 28.7 & 0.578 & 241 & 22.7 & 44.76 & 8.01 & 5.59 & 31.31 & 1.43 & 32.37 & 1.38 \\
\hline RB20 & 68.3 & 76 & 47.9 & 0.578 & 241 & 22.7 & 57.79 & 8.13 & 7.11 & 44.30 & 1.30 & 47.34 & 1.22 \\
\hline RB21 & 68.3 & 76 & 18.1 & 0.924 & 241 & 22.7 & 37.49 & 12.08 & 3.10 & 24.92 & 1.50 & 26.97 & 1.39 \\
\hline RB22 & 68.3 & 76 & 30.2 & 0.924 & 241 & 22.7 & 43.76 & 12.56 & 3.48 & 34.72 & 1.26 & 37.51 & 1.17 \\
\hline RB23 & 68.3 & 76 & 56.3 & 0.924 & 241 & 22.7 & 63.46 & 12.89 & 4.92 & 51.57 & 1.23 & 57.89 & 1.1 \\
\hline RB24 & 42.6 & 51 & 51.8 & 0.371 & 241 & 22.7 & 18.52 & 2.05 & 9.03 & 14.77 & 1.25 & 17.13 & 1.08 \\
\hline RB25 & 42.6 & 51 & 26.3 & 0.371 & 241 & 22.7 & 14.16 & 2.02 & 7.01 & 10.68 & 1.33 & 10.81 & 1.31 \\
\hline RB26 & 68.3 & 76 & 52 & 0.231 & 241 & 22.7 & 55.31 & 3.29 & 16.81 & 43.84 & 1.26 & 45.23 & 1.22 \\
\hline \multirow[t]{4}{*}{ RB27 } & 68.3 & 76 & 25.7 & 0.231 & 241 & 22.7 & 37.01 & 3.27 & 11.32 & 26.69 & 1.39 & 27.14 & 1.36 \\
\hline & & & & & & & & Avg. & 6.0 & & 1.25 & & 1.18 \\
\hline & & & & & & & & St. Dev. & 3.6 & & 0.12 & & 0.13 \\
\hline & & & & & & & & C.O.V. & 0.60 & & 0.10 & & 0.11 \\
\hline
\end{tabular}

Table 2. Comparison between the experimental and predicted failure loads of Birke's [17] specimens

\begin{tabular}{|c|c|c|c|c|c|c|c|c|c|c|c|}
\hline STRIP & $\mathrm{h}$ & $\mathrm{f}_{\mathrm{cu}}$ & $\rho$ & $f_{y}$ & $\mathrm{k}$ & $\mathrm{P}_{\mathrm{T}}$ & $\mathrm{P}_{\mathrm{b}}$ & $\mathrm{P}_{\mathrm{Q}}$ & $\mathrm{P}_{\mathrm{T}}$ & $\mathrm{P}_{\mathrm{FEA}}$ & $\mathrm{P}_{\mathrm{T}}$ \\
\hline NO. & $\mathrm{mm}$ & $\mathrm{N} / \mathrm{mm}^{2}$ & & & $\mathrm{kN} / \mathrm{mm}^{2}$ & $\mathrm{kN}$ & $\mathrm{kN}$ & $\mathrm{kN}$ & $/ \mathrm{P}_{\mathrm{Q}}$ & $\mathrm{kN}$ & $/ \mathrm{P}_{\mathrm{FEA}}$ \\
\hline B21/22 & 19.4 & 22.8 & - & - & $\infty$ & 2.25 & - & 1.82 & 1.24 & 1.95 & 1.15 \\
\hline B31/C32 & 29.9 & 27.8 & - & - & $\infty$ & 7.1 & - & 5.66 & 1.25 & 6.04 & 1.18 \\
\hline B32/C31 & 29.7 & 36.6 & - & - & $\infty$ & 8.85 & - & 7.16 & 1.24 & 7.47 & 1.18 \\
\hline $\mathrm{C} 21 / 22$ & 20.4 & 37.3 & - & - & $\infty$ & 4.24 & - & 3.11 & 1.36 & 3.34 & 1.27 \\
\hline C51/52 & 50 & 32.5 & - & - & $\infty$ & 24.17 & - & 19.57 & 1.24 & 19.75 & 1.22 \\
\hline D21/22 & 20.5 & 36.3 & - & - & $\infty$ & 4.37 & - & 3.07 & 1.42 & 3.3 & 1.32 \\
\hline D31/32 & 31 & 32.4 & - & - & $\infty$ & 10.73 & - & 7.04 & 1.52 & 7.47 & 1.44 \\
\hline D51/52 & 50 & 34.8 & - & - & $\infty$ & 22.06 & - & 20.89 & 1.06 & 21.05 & 1.05 \\
\hline $\mathrm{E} 20 / 21$ & 20 & 22.4 & - & - & $\infty$ & 2.56 & - & 1.92 & 1.33 & 2.13 & 1.2 \\
\hline \multirow[t]{4}{*}{ E10-19 } & 10.7 & 22.4 & - & - & $\infty$ & 0.49 & - & 0.43 & 1.14 & 0.53 & 0.93 \\
\hline & & & & & & & & Avg. & 1.28 & & 1.19 \\
\hline & & & & & & & & St. Dev. & 0.14 & & 0.14 \\
\hline & & & & & & & & C.O.V. & 0.11 & & 0.12 \\
\hline
\end{tabular}


Table 3. Comparison between the experimental and predicted failure loads of Taylor's [14] specimens

\begin{tabular}{|c|c|c|c|c|c|c|c|c|c|c|c|c|c|c|}
\hline Strip & d & $\mathrm{f}_{\mathrm{cu}}$ & $\rho$ & $\mathrm{k}$ & Boundary & $\mathrm{P}_{\mathrm{T}}$ & $\mathrm{P}_{\mathrm{b}}$ & $\mathrm{P}_{\mathrm{T}}$ & $\mathrm{P}_{\mathrm{Q}}$ & $\mathrm{P}_{\mathrm{T}}$ & $\mathrm{P}_{\mathrm{FER}}$ & $\mathrm{P}_{\mathrm{T}}$ & $\mathrm{P}_{\mathrm{FEA}}$ & $\mathrm{P}_{\mathrm{T}}$ \\
\hline No. & $\mathrm{mm}$ & $\mathrm{N} / \mathrm{mm}^{2}$ & $\%$ & $\mathrm{kN} / \mathrm{mm}^{2}$ & Condition & $\mathrm{kN}$ & $\mathrm{kN}$ & $\begin{array}{l}1 \\
\mathrm{P}_{\mathrm{b}}\end{array}$ & $\mathrm{kN}$ & $\begin{array}{c}1 \\
\mathrm{P}_{\mathrm{Q}} \\
\end{array}$ & $\mathrm{kN}$ & $\begin{array}{c}1 \\
\mathrm{P}_{\mathrm{FER}}\end{array}$ & $\mathrm{kN}$ & $\begin{array}{c}1 \\
\mathrm{P}_{\mathrm{FEA}}\end{array}$ \\
\hline S1 & 104 & 31.20 & $0.687 \mathrm{~TB}$ & 197.00 & $\mathrm{FE}+\mathrm{L} / \mathrm{R}$ & 135 & 91.5 & 1.48 & 124 & 1.09 & 136 & 0.99 & 133 & 1.02 \\
\hline S2 & 104 & 40.80 & $0.687 \mathrm{~TB}$ & 197.00 & $\mathrm{FE}+\mathrm{L} / \mathrm{R}$ & 145 & 93.4 & 1.55 & 136 & 1.07 & 151 & 0.96 & 150 & 0.97 \\
\hline S3 & 104 & 64.50 & 0.687 TВ & 197.00 & $\mathrm{FE}+\mathrm{L} / \mathrm{R}$ & 175 & 95.7 & 1.83 & 153 & 1.14 & 174 & 1.01 & 170 & 1.03 \\
\hline S4 & 104 & 82.20 & $0.687 \mathrm{~TB}$ & 197.00 & $\mathrm{FE}+\mathrm{L} / \mathrm{R}$ & 187 & 96.6 & 1.94 & 161 & 1.16 & 184 & 1.02 & 185 & 1.01 \\
\hline S5 & 104 & 101.10 & $0.687 \mathrm{~TB}$ & 197.00 & $\mathrm{FE}+\mathrm{L} / \mathrm{R}$ & 192 & 97.1 & 1.98 & 168 & 1.14 & 198 & 0.97 & 195 & 0.99 \\
\hline S6 & 104 & 34.80 & $0.687 \mathrm{~B}$ & - & $\mathrm{S} / \mathrm{S}$ & 46 & 46.2 & 1.00 & $\begin{array}{c}46.2 \\
0 \\
\end{array}$ & 1.00 & 46 & 1.00 & 49 & 0.94 \\
\hline S7 & 104 & 91.00 & $0.687 \mathrm{~B}$ & - & $\mathrm{S} / \mathrm{S}$ & 50 & 48.4 & 1.03 & $\begin{array}{c}48.5 \\
0 \\
\end{array}$ & 1.03 & 59 & 0.85 & 57.5 & 0.87 \\
\hline $\mathrm{S} 8$ & 104 & 100.10 & $0.687 \mathrm{~B}$ & 197.00 & $\mathrm{~S} / \mathrm{S}+\mathrm{L} / \mathrm{R}$ & 183 & 72.8 & 2.51 & 143 & 1.28 & 188 & 0.97 & 158 & 1.16 \\
\hline S9 & 104 & 89.30 & $0.687 \mathrm{~TB}$ & 410.00 & $\mathrm{FE}+\mathrm{L} / \mathrm{R}$ & 252 & 96.8 & 2.60 & 206 & 1.22 & 242 & 1.04 & 221 & 1.14 \\
\hline S10 & - & 90.50 & - & 410.00 & $\mathrm{FE}+\mathrm{L} / \mathrm{R}$ & 200 & - & - & 135 & 1.48 & 191 & 1.05 & 167 & 1.20 \\
\hline S11 & 75 & 96.80 & $0.953 \mathrm{C}$ & 410.00 & $\mathrm{FE}+\mathrm{L} / \mathrm{R}$ & 223 & 69.2 & 3.22 & 185 & 1.21 & 237 & 0.94 & 201 & 1.11 \\
\hline $\mathrm{S} 12$ & 104 & 101.00 & $0.687 \mathrm{~TB}$ & 410.00 & $\mathrm{FE}+\mathrm{L} / \mathrm{R}$ & 500 & 194.3 & 2.57 & 434 & 1.15 & 498 & 1.00 & 504 & 0.99 \\
\hline $\mathrm{S} 14$ & 104 & 39.50 & $0.687 \mathrm{~TB}$ & 410.00 & $\mathrm{FE}+\mathrm{L} / \mathrm{R}$ & 195 & 93.2 & 2.09 & 151 & 1.29 & 168 & 1.16 & 159 & 1.22 \\
\hline S15 & 104 & 60.90 & $0.687 \mathrm{~TB}$ & 410.00 & $\mathrm{FE}+\mathrm{L} / \mathrm{R}$ & 211 & 95.5 & 2.21 & 179 & 1.18 & 197 & 1.07 & 195 & 1.08 \\
\hline \multicolumn{3}{|c|}{ TB $\rightarrow$ Top and Bottom } & & & & & \multirow{2}{*}{ Avg. } & \multirow{2}{*}{2.00} & & \multirow{2}{*}{1.17} & & \multirow{2}{*}{1.00} & & \multirow{2}{*}{1.05} \\
\hline \multicolumn{3}{|c|}{$\mathrm{C} \rightarrow$ Mid-Depth } & & & & & & & & & & & & \\
\hline \multicolumn{3}{|c|}{$\mathrm{FE} \rightarrow$ Fixed End } & & & & & \multirow{2}{*}{ St. Dev. } & \multirow{2}{*}{0.64} & & \multirow{2}{*}{0.12} & & \multirow{2}{*}{0.07} & & \multirow{2}{*}{0.10} \\
\hline \multicolumn{3}{|c|}{$\mathrm{L} / \mathrm{R} \rightarrow$ Lateral Restraint } & & & & & & & & & & & & \\
\hline \multicolumn{3}{|c|}{ S/S $\rightarrow$ Simple Support } & & & & & \multirow{2}{*}{ C.O.V } & \multirow{2}{*}{0.32} & & \multirow{2}{*}{0.10} & & \multirow{2}{*}{0.07} & & \multirow{2}{*}{0.10} \\
\hline & $h \rightarrow$ & $\mathrm{mm}$ & & & & & & & & & & & & \\
\hline
\end{tabular}

Table 4. Comparison between experimental and predicted failure loads of Rankin's [6] large panel specimens

\begin{tabular}{|c|c|c|c|c|c|c|c|c|c|c|}
\hline SLAB & d & $\mathrm{h}$ & $\mathrm{f}_{\mathrm{cu}}$ & $f_{y}$ & $\rho$ & $\mathrm{P}_{\mathrm{T}}$ & $\mathrm{P}_{\mathrm{Q}}$ & $\mathrm{P}_{\mathrm{T}}$ & $\mathrm{P}_{\mathrm{FEA}}$ & $\mathrm{P}_{\mathrm{T}}$ \\
\hline NO. & $\mathrm{mm}$ & $\mathrm{mm}$ & $\mathrm{N} / \mathrm{mm}^{2}$ & $\mathrm{~N} / \mathrm{mm}^{2}$ & $\%$ & $\mathrm{kN}$ & $\mathrm{kN}$ & $/ \mathrm{P}_{\mathrm{Q}}$ & $\mathrm{kN}$ & $/ \mathrm{P}_{\mathrm{FEA}}$ \\
\hline R1-08 & 40.5 & 51 & 37.7 & 530 & 0.802 & 65.22 & 45.20 & 1.44 & 52.88 & 1.23 \\
\hline R2-08 & 40.5 & 51 & 38.9 & 530 & 0.802 & 64.81 & 55.34 & 1.17 & 58.4 & 1.11 \\
\hline R3-08 & 40.5 & 51 & 41.1 & 530 & 0.802 & 69.66 & 61.97 & 1.12 & 66.4 & 1.05 \\
\hline R4-08 & 40.5 & 51 & 33.5 & 530 & 0.802 & 71.47 & 56.73 & 1.26 & 64.16 & 1.11 \\
\hline R5-08 & 40.5 & 51 & 53.8 & 530 & 0.802 & 77.84 & 77.45 & 1.01 & 83.16 & 0.94 \\
\hline $\mathrm{R} 2-11$ & 40.5 & 51 & 40.1 & 530 & 1.107 & 69.73 & 63.08 & 1.11 & 70.4 & 0.99 \\
\hline R4-11 & 40.5 & 51 & 43.6 & 530 & 1.107 & 81.59 & 71.66 & 1.14 & 82.5 & 0.99 \\
\hline R5-11 & 40.5 & 51 & 38.9 & 530 & 1.107 & 87.89 & 67.20 & 1.31 & 80 & 1.1 \\
\hline R3-05 & 40.5 & 51 & 38.5 & 530 & 0.517 & 56.16 & 51.41 & 1.09 & 51.6 & 1.09 \\
\hline R5-05 & 40.5 & 51 & 38.5 & 530 & 0.517 & 62.51 & 56.92 & 1.10 & 61.2 & 1.02 \\
\hline R3A-08 & 46.5 & 57 & 38.3 & 530 & 0.800 & 96.41 & 78.83 & 1.22 & 85.2 & 1.13 \\
\hline R5A-08 & 46.5 & 57 & 39.6 & 530 & 0.800 & 95.34 & 84.99 & 1.12 & 95.16 & 1 \\
\hline R3B-08 & 35 & 45.5 & 36.9 & 530 & 0.799 & 55.22 & 43.40 & 1.27 & 48 & 1.15 \\
\hline R5B-08 & 35 & 45.5 & 39.4 & 530 & 0.799 & 60.34 & 47.99 & 1.26 & 56 & 1.08 \\
\hline $\mathrm{R} 3 \mathrm{C}-08$ & 53.5 & 64 & 41.3 & 530 & 0.800 & 112.47 & 109.39 & 1.03 & 113 & 1 \\
\hline R5C-08 & 53.5 & 64 & 44.1 & 530 & 0.800 & 126.27 & 116.78 & 1.08 & 128.1 & 0.99 \\
\hline & & & & & & & Avg. & 1.17 & & 1.06 \\
\hline & & & & & & & St. Dev. & 0.11 & & 0.08 \\
\hline & & & & & & & C.O.V & 0.10 & & 0.07 \\
\hline
\end{tabular}


Table 5. Comparison between the experimental and predicted failure loads of Rankin's [6] contraflexure specimens

\begin{tabular}{|c|c|c|c|c|c|c|c|c|c|c|}
\hline SLAB & d & $\mathrm{h}$ & $\mathrm{f}_{\mathrm{cu}}$ & $\mathrm{f}_{\mathrm{y}}$ & $\rho$ & $\mathrm{P}_{\mathrm{T}}$ & $\mathrm{P}_{\mathrm{Q}}$ & $\mathrm{P}_{\mathrm{T}}$ & $\mathrm{P}_{\mathrm{FEA}}$ & $\mathrm{P}_{\mathrm{T}}$ \\
\hline NO. & $\mathrm{mm}$ & $\mathrm{mm}$ & $\mathrm{N} / \mathrm{mm}^{2}$ & $\mathrm{~N} / \mathrm{mm}^{2}$ & $\%$ & $\mathrm{kN}$ & $\mathrm{kN}$ & $/ \mathrm{P}_{\mathrm{Q}}$ & $\mathrm{kN}$ & $/ \mathrm{P}_{\mathrm{FEA}}$ \\
\hline 1 & 40.5 & 51 & 38.4 & 530 & 0.423 & 36.42 & 28.2 & 1.29 & 31.6 & 1.15 \\
\hline 2 & 40.5 & 51 & 38.4 & 530 & 0.558 & 49.08 & 35.3 & 1.39 & 37.08 & 1.32 \\
\hline 3 & 40.5 & 51 & 38.4 & 530 & 0.691 & 56.55 & 41.5 & 1.36 & 42.43 & 1.33 \\
\hline 4 & 40.5 & 51 & 43.5 & 530 & 0.821 & 56.18 & 48.3 & 1.16 & 48.96 & 1.15 \\
\hline 5 & 40.5 & 51 & 43.5 & 530 & 0.883 & 57.27 & 50.9 & 1.12 & 51.27 & 1.12 \\
\hline 6 & 40.5 & 51 & 43.5 & 530 & 1.026 & 65.58 & 56.1 & 1.17 & 57.20 & 1.15 \\
\hline 7 & 40.5 & 51 & 37.1 & 530 & 1.163 & 70.94 & 53.5 & 1.33 & 59.60 & 1.19 \\
\hline 8 & 40.5 & 51 & 37.1 & 530 & 1.292 & 71.09 & 54.9 & 1.29 & 63.20 & 1.12 \\
\hline 9 & 40.5 & 51 & 37.1 & 530 & 1.454 & 78.60 & 56.5 & 1.39 & 68.21 & 1.15 \\
\hline 10 & 40.5 & 51 & 37.4 & 530 & 0.517 & 43.59 & 33.1 & 1.32 & 35.00 & 1.25 \\
\hline 11 & 40.5 & 51 & 37.4 & 530 & 0.802 & 55.00 & 45.7 & 1.20 & 46.20 & 1.19 \\
\hline 12 & 40.5 & 51 & 37.4 & 530 & 1.107 & 67.06 & 53.0 & 1.26 & 57.84 & 1.16 \\
\hline 13 & 40.5 & 51 & 42.5 & 530 & 0.601 & 49.39 & 38.1 & 1.30 & 40.08 & 1.23 \\
\hline 14 & 40.5 & 51 & 42.5 & 530 & 0.691 & 52.45 & 42.4 & 1.24 & 43.50 & 1.21 \\
\hline 15 & 40.5 & 51 & 42.5 & 530 & 1.994 & 84.84 & 65.5 & 1.29 & 86.10 & 0.99 \\
\hline $1 \mathrm{~A}$ & 57 & 46.5 & 36 & 530 & 0.422 & 45.19 & 36.7 & 1.23 & 38.75 & 1.17 \\
\hline $2 \mathrm{~A}$ & 57 & 46.5 & 36 & 530 & 0.691 & 66.24 & 53.8 & 1.23 & 52.80 & 1.25 \\
\hline $3 \mathrm{~A}$ & 57 & 46.5 & 36 & 530 & 1.293 & 89.72 & 64.7 & 1.39 & 82.00 & 1.09 \\
\hline $4 \mathrm{~A}$ & 57 & 46.5 & 38.6 & 530 & 1.992 & 97.43 & 74.7 & 1.30 & 106.32 & 0.92 \\
\hline $1 \mathrm{~B}$ & 45.5 & 35 & 47.1 & 530 & 0.423 & 28.85 & 21.6 & 1.34 & 25.67 & 1.12 \\
\hline $2 \mathrm{~B}$ & 45.5 & 35 & 47.1 & 530 & 0.690 & 37.63 & 32.3 & 1.16 & 34.40 & 1.09 \\
\hline $3 \mathrm{~B}$ & 45.5 & 35 & 47.1 & 530 & 1.292 & 56.67 & 49.4 & 1.15 & 51.48 & 1.10 \\
\hline $4 B$ & 45.5 & 35 & 38.6 & 530 & 1.994 & 72.52 & 51.8 & 1.40 & 63.90 & 1.13 \\
\hline $1 \mathrm{C}$ & 64 & 53.5 & 34.8 & 530 & 0.423 & 62.74 & 48.5 & 1.29 & 49.00 & 1.28 \\
\hline $2 \mathrm{C}$ & 64 & 53.5 & 40.5 & 530 & 0.690 & 87.86 & 70.7 & 1.24 & 71.10 & 1.24 \\
\hline $3 \mathrm{C}$ & 64 & 53.5 & 40.5 & 530 & 1.288 & 124.14 & 82.7 & 1.50 & 111.15 & 1.12 \\
\hline \multirow[t]{4}{*}{$4 \mathrm{C}$} & 64 & 53.5 & 34.8 & 530 & 1.993 & 125.94 & 85.4 & 1.47 & 136.04 & 0.93 \\
\hline & & & & & & & Avg. & 1.29 & & 1.15 \\
\hline & & & & & & & St. Dev. & 0.10 & & 0.10 \\
\hline & & & & & & & C.O.V. & 0.08 & & 0.09 \\
\hline
\end{tabular}



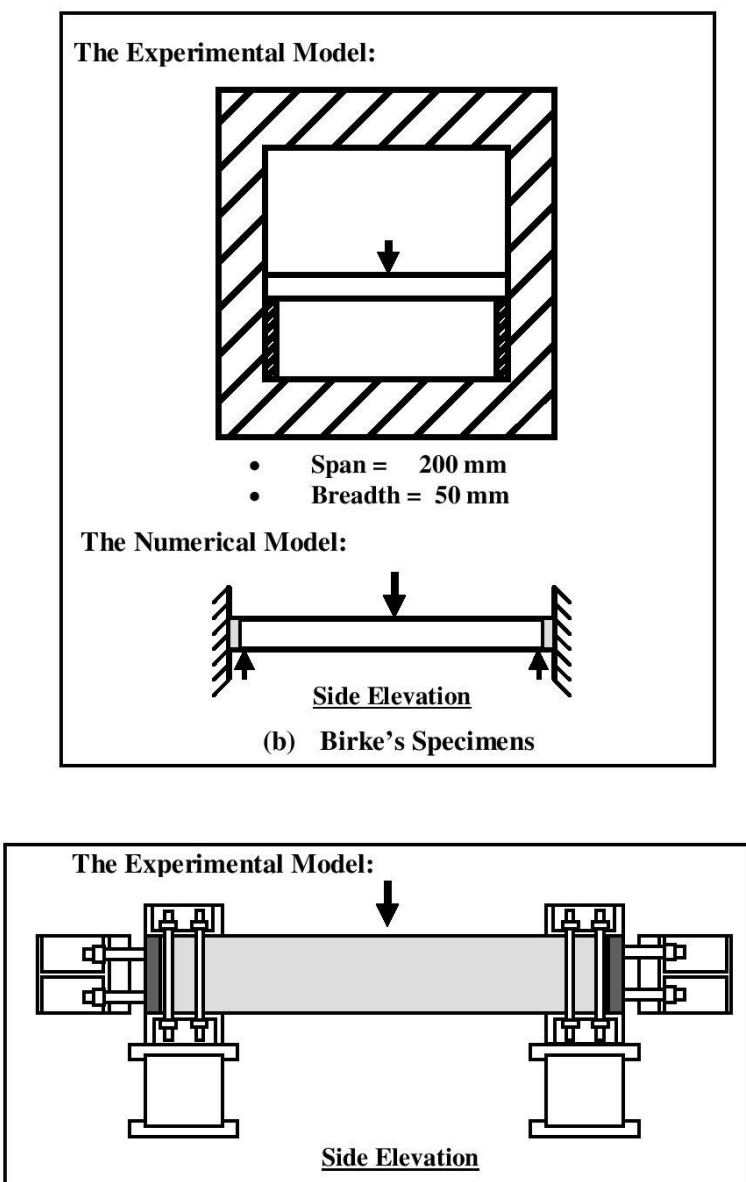

The Numerical Model:

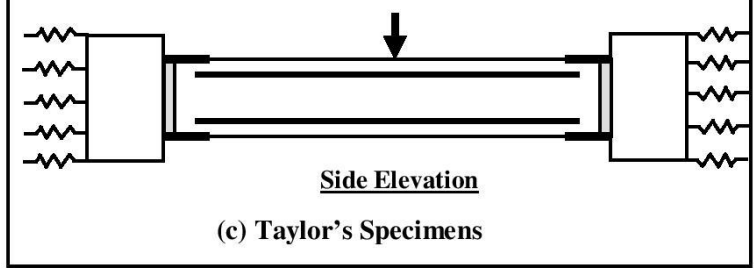

Nominal tension of only $0.01 \mathrm{~N} / \mathrm{mm}^{2}$ was allowed at the contact

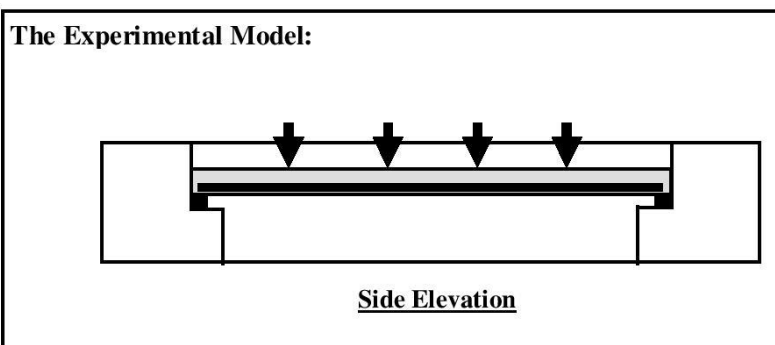

The Nume rical Model:

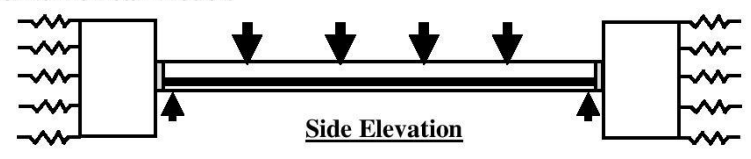

(a) Roberts's Specimens

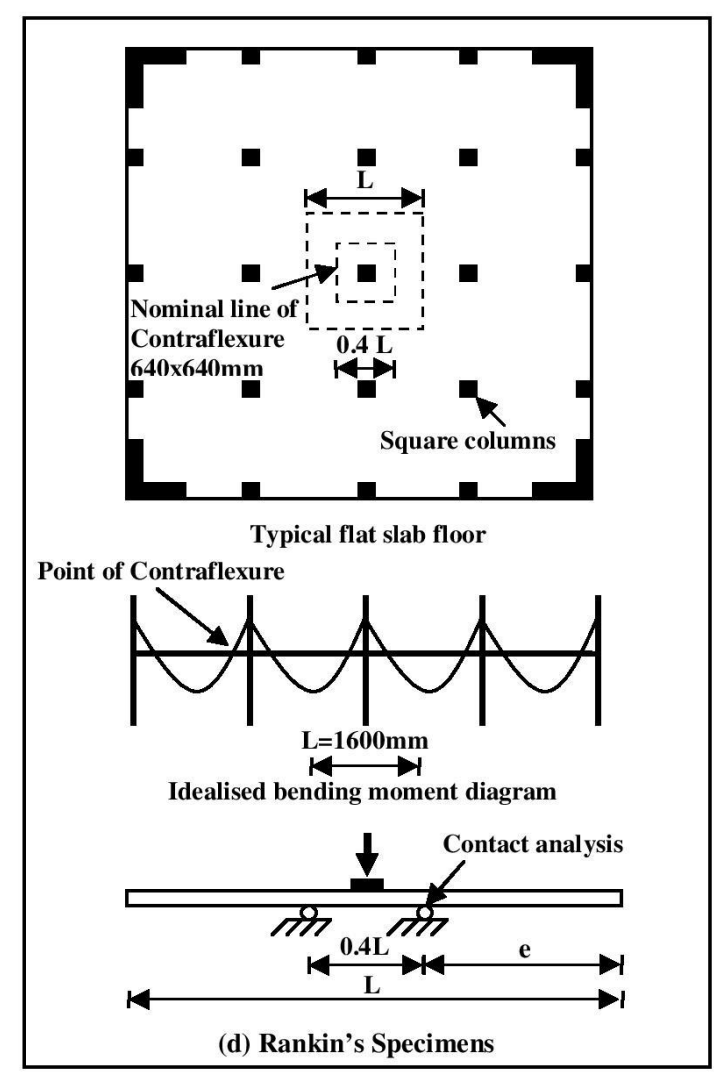

Figure 2. The experimental and simplified numerical models

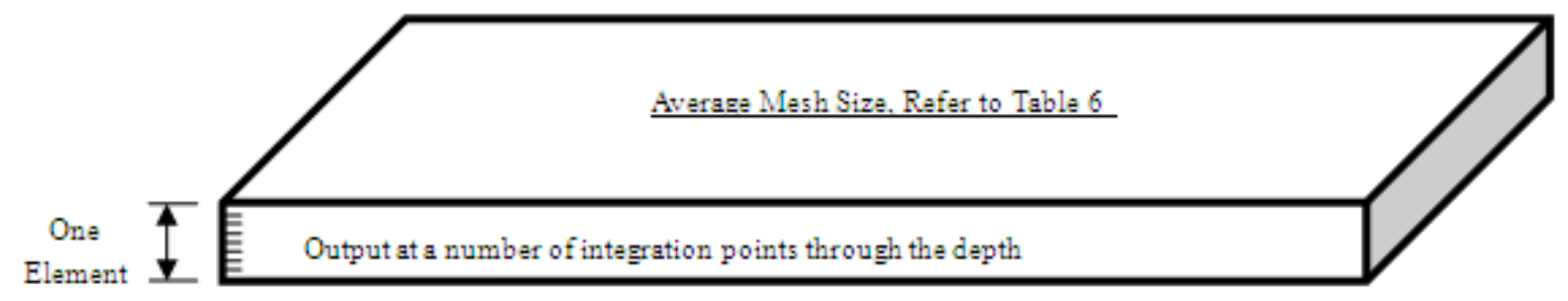

Figure 3. Finite Element Mesh Layout/Description 


\subsection{Geometry}

\subsubsection{Mesh Size}

The mesh size was checked for sensitivity of the analysis to element size. This was done by considering the effect of different sizes of elements on the numerical predictions. The element size that caused minimum or insignificant variation to the numerical predictions was adopted; refer to Figure 3 and Table 6 for details on the mesh size used for every slab configuration considered in this study.

Table 6. Description of Mesh Size

\begin{tabular}{|c|c|}
\hline Slab Configuration & Average Mesh Size (mm) \\
\hline Roberts & 25 \\
\hline Birke & 5 \\
\hline Taylor & 25 \\
\hline Rankin & 50 \\
\hline
\end{tabular}

For Birke specimens an average element size of $5 \mathrm{~mm}$ was used as the specimens were geometrically very small and therefore the adopted small mesh size did not have a significant impact on the overall computational timing. For the larger Roberts and Taylor specimens, an average mesh size of $25 \mathrm{~mm}$ was used. However, for Rankin specimens, as they were relatively larger, an average mesh size of $50 \mathrm{~mm}$ was used after conducting a sensitivity analysis showing a small difference in accuracy of predictions ( $2 \%$ on average) between the two mesh sizes (i.e. $25 \mathrm{~mm}$ and $50 \mathrm{~mm}$ ).

\subsubsection{Element Type}

4-node 3-D shell elements with six degrees of freedom were used to analyze each slab. This element type was found to be adequate for the purpose of simulation and produced a great saving in computational time and cost compared to 3-D brick or solid continuum elements, particularly with the reduced integration option, without affecting the accuracy of the output. Hourglass control was used with the reduced integration elements to prevent distortion. Although 2-D solid elements with plane stress or plane strain can also be used, in either case the accuracy of the results might be questioned due to the assumption made for the third dimension and this type of element could not be used in the case of two-way slabs. The 4-node 3-D general shell element with reduced integration and hourglass control could be utilised for the simulation of thin or thick slabs with relevance to shear deformation (S4R).

Although S4R is represented graphically in a two dimensional space, the behaviour over the depth was calculated by numerical integration through the shell thickness by dividing it into several integration points (refer to Figure 3). Numerical equations are solved at every integration point to analyse the stress-strain variation through the depth. Sensitivity analysis was carried out for the different types of the investigated specimens and concluded that nine integration points were adequate to accurately simulate the behaviour of the investigated slab specimens of Roberts [16], Birke [17] and Rankin [6], while 13 points were used for Taylor's [14] specimens as they produced better accuracy of the simulation. The use of a bigger number of integration points produces better accuracy but increases analysis time. Using a greater number of integration points was found to cause an insignificant variation in the numerical predictions $(\sim 1 \%-2 \%$ on average). The shell section integration is defined either by Simpson's rule or Gauss quadrature; the latter was not used as it does not allow results to be output on the shell surfaces.

Reinforcement was modelled as a smeared layer with a constant thickness equal to the area of each reinforcing bar divided by the reinforcing bar spacing. The area, spacing and location of the reinforcing bars within the depth were defined by the user in advance.

\subsection{Material Properties}

ABAQUS [5] offered three established models for reinforced concrete. The titles used to identify them in this paper are the same as those used in the ABAQUS documentation $[18,19]$.

1 - The Cracking model for Concrete,

The Cracking model employs a smeared crack model to simulate discontinuous brittle behaviour. This model allows for the removal of cracked elements from the mesh, which removes computationally difficult parts from the analysis. However in this model compressive behaviour can only be linear elastic, which makes the modelling of non linear plastic compression behaviour impossible.

2 - The Concrete Smeared Cracking model,

The Concrete Smeared Cracking model consists of an isotropically hardening yield surface that is active when the stress is dominantly compressive and an independent crack detection surface that determines if a point fails by cracking. The reversible part of the material's response after cracking failure is described by damaged plasticity concepts.

3 - The Damaged Plasticity model,

The Damaged Plasticity model can be considered as an upgraded version of the Concrete Smeared Cracking model. It consists of the combination of non-associated hardening plasticity and scalar (isotropic) damaged elasticity to describe the irreversible damage that occurs during the fracturing process. The Damaged Plasticity model also allows for stiffness recovery effects during cyclic load reversals (cyclic loading was not investigated in this paper).

A distinguishing difference between the second and third models is that the second model assumes an associated potential flow and yield (hardening) function, while the third model assumes a non-associated potential flow function and uses an independent yield (hardening) function which is aimed at providing a more realistic simulation of the concrete. Therefore, the third model, i.e. the Damaged Plasticity model, was decided to be used in this study.

This Damaged Plasticity model requires definition of the 
following parameters:

- Elastic values of concrete (Young's modulus and Poisson's ratio), see Figure 4.

- Plasticity parameters: default values as proposed by ABAQUS $[18,19]$ for the plasticity model were used and they are defined as follows (these parameters are not intended to be discussed in further details in this paper):

- Dilation angle $=15$ degrees.

- Flow potential eccentricity $=0.1$. The eccentricity is a small positive number that defines the rate at which the hyperbolic flow potential approaches its asymptote.

- Stress ratio, which is required to define the yield surface in the plasticity model, this ratio must be between 0.5 and 1.0 , where the default value used was 0.67 .

- The ratio of the initial equibiaxial compressive yield stress to initial uniaxial compressive yield stress, where a value of 1.0 was used for one-way spanning slabs and a value of 1.16 was used for the modelling of two-way spanning slabs as was proposed by ABAQUS Analysis manual [19].

- Full stress-strain curve of concrete including the elastic, hardening and softening stages, both for compression and tension allowing for tension stiffening (Figure 4). The stress-strain curve of concrete in compression was defined using the equation developed by Desayi and Krishnan [20] and recommended by Neville [21] for the hardening part, while the softening part was defined as proposed by Mattock et al [22] and reported by Park and Paulay [23].

For the stress-strain properties in tension a simple tension stiffening model that defines a linear loss of strength beyond the cracking point of the concrete was used. The cracking stress was estimated using the relationship reported by Neville [21]. The ultimate tensile strain was kept constant at 2500 micro strain for all the specimens, as proposed by Scott [24]. It was important to keep the slope of the descending part of the stress-strain curve of concrete in tension as shallow as possible to avoid numerical instability and convergence problems without affecting the overall accuracy of the analysis.

Sensitivity analyses were carried out to study the effect of the termination strain on the simulation (Figure 4). The effect of the softening part of the compression behaviour on the numerical predictions of the ultimate load was not very significant $(1 \%-2 \%$ on average $)$ because failure was characterised around the peak compressive stress. However, convergence was found difficult for values of $3.8 \mathrm{E}-3$ and $6 \mathrm{E}-3$, while values of $8 \mathrm{E}-3$ and $1 \mathrm{E}-2$ resulted in fairly similar results with good convergence. These values correspond to points 1, 2, 3 and 4 in Figure 4. The latter value was used as it resulted in a faster convergence rate.

On the other hand, for the tension behaviour of reinforced concrete, slightly smaller (2E-3) and bigger (3E-3) values to the value recommended by Scott [24] were considered and found to have an insignificant effect on the numerical predictions. For plain concrete, a sensitivity study was carried out considering reduced strains in tension compared with reinforced concrete of $6 \mathrm{E}-4,8 \mathrm{E}-4$ and $1 \mathrm{E}-3$. These levels of termination strains were within reasonable agreement to those reported by Guo and Zhang [25]. The first value caused convergence problems, while the other two gave similar results and therefore the latter was used for ease of convergence.

Termination Stress was specified as $1 \%$ of the yield compressive strength in case of compression behaviour and $1 \%$ of the cracking stress in case of tension behaviour. However, for tension behaviour it was assumed by the authors to be $0.1 \mathrm{~N} / \mathrm{mm}^{2}$ for all the specimens to enhance the analysis speed without affecting the numerical predictions.
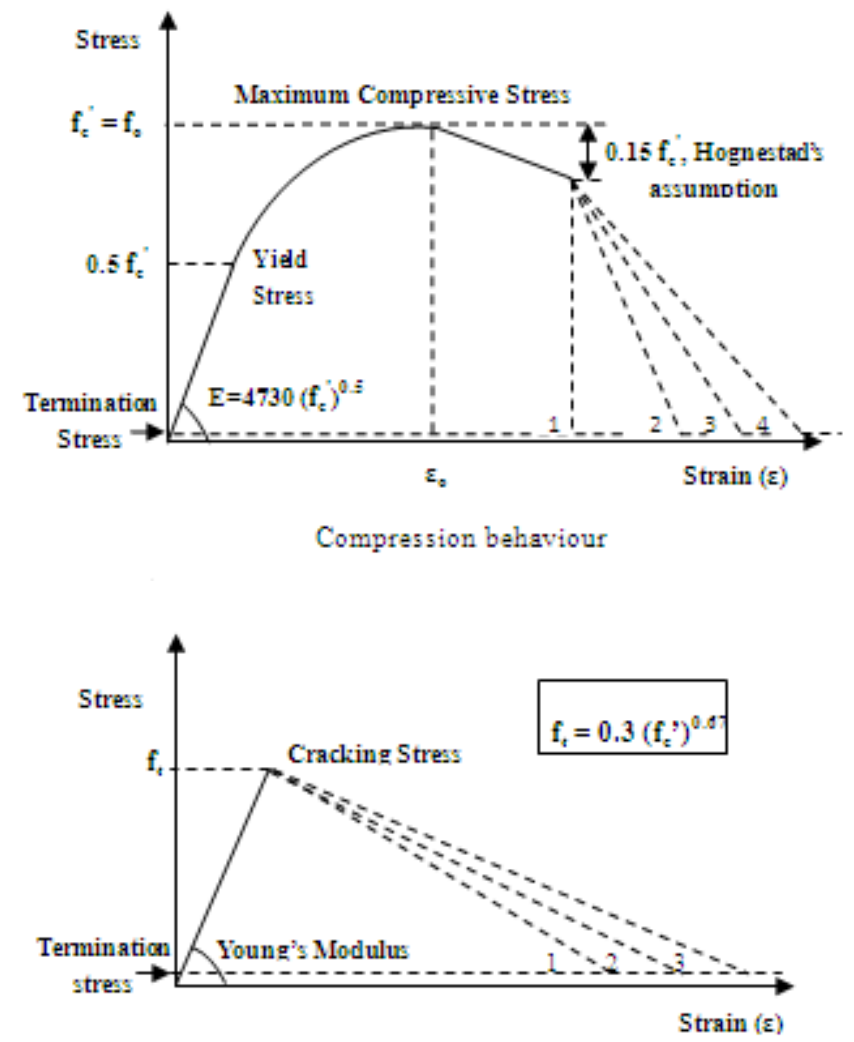

Tension behaviour

Figure 4. Material Properties

\subsection{Edge/boundary Conditions}

In experiments it has been observed that as the slab deforms under load the top of the slab moves away from the end restraint while the compressive stresses at the bottom increase [12]. An alternative way of explaining this is that the centre of action of the in-plane end restraint moves downward as loading progresses. This is a classical contact analysis problem which can be catered for by ABAQUS analysis. Such contact analysis is generally presented in 
Figure 5 which also shows a compressive arch developing across the depth of a restrained slab strip.

For the one-way spanning slab strips investigated in this paper, a contact analysis was initially investigated; this allowed the transmission of the in-plane compression forces only between the slab edge and the surrounding boundary. However the implicit static analysis encountered convergence problems with the complex nonlinear contact conditions associated with the one-way slabs investigated in addition to prolonged analyses durations. Therefore, it was necessary to simplify the numerical representation of the experimental models to avoid any complicated nonlinear contact analysis.

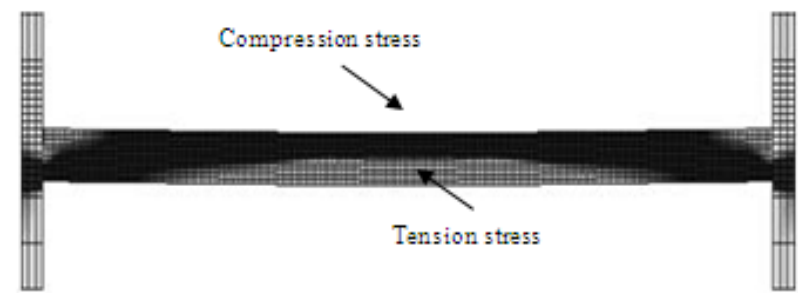

Figure 5. Typical contact analysis of a laterally restrained slab strip showing the development of an arch (Stress versus Load)

The tensile strength capacity of the elements in the region of the support was modified so that they had reduced strength in tension $\left(0.1 \mathrm{~N} / \mathrm{mm}^{2}\right)$. Setting the tension strength of these end elements to zero would not have allowed the analysis to converge. As a result of this simplification, only in-plane compression and very insignificant in-plane tension could develop at the ends, as illustrated in Figure 2, which shows the experimental models investigated as well as the simplified numerical models. These simplifications helped the nonlinear implicit static analysis to converge without affecting the accuracy of the simulation. While the lateral restraint stiffness of Birke's [17] specimens was assumed infinite, springs elements were used to simulate the reported lateral restraint stiffness of Roberts [16] and Taylor's [14] specimens.

For the two-way spanning slabs of Rankin [6], a contact analysis was used as offered by ABAQUS to simulate the relationship between each slab specimen and the supporting square steel rig (refer to Figure 2(d)). The user has to define the contact constraints to suit the requirements of the simulation. The defined contact analysis allowed for the transmission of vertical forces and permitted lift up at the corners of the rig, which was observed experimentally. This contact analysis did not cause convergence problems or prolonged analysis duration probably because the contact was vertical rather than horizontal and there was a very limited (small) width of contact as illustrated in Figure 2(d).

\subsection{Failure Criterion}

As the numerical analysis did not automatically stop, a failure criterion had to be established. Even load versus mid-span deflection graphs cannot be effectively used to determine failure, because the loading procedure in the ABAQUS General Static Method [5] is such that the load does not reduce. Instead the graph generally forms a plateau at ultimate with mid-span deflection increasing rapidly. The reason why the numerical analysis did not necessarily stop at failure was because of the assumed softening regimes which do not reach a value of zero; these were required to achieve convergence and to avoid numerical instability.

Thus, for the one-way spanning slabs, numerical failure was assumed to occur when the slab could not bear any more compression, i.e. reached a peak value of compressive stress, at mid-span and at the supports (compressive strut mechanism). These compressive failures, at mid-span and at the supports, occurred after yielding of the reinforcement at these critical sections. This failure mode was indicated by and applies to Robert's [16], Taylor's [14] and Birkes's [17] test specimens that were laterally restrained, except that Birke's specimens were unreinforced. This failure criterion is typical of laterally restrained slabs. Unrestrained specimens were assumed to fail when reinforcement has yielded. This assumption was found to give consistently accurate predictions. This criterion could be automatically set in ABAQUS by limiting the stress at a specific element to a certain known value.

For the two-way spanning slabs under concentrated loading, all the slabs tested by Rankin [6] and other researchers such as Masterson and Long [26] were reported to fail by punching. However, depending on many factors such as, reinforcement percentage, amount of restraint provided and concrete strength, this punching mode of failure varied from being ductile to brittle with local crushing of concrete around the loading plate. Generally, punching as reported in literature (e.g. Rankin [6] and Shaat [15]) was characterised by yielding of reinforcement and crushing of the concrete at the perimeter of the loaded area (or column) at the centre of the slab prior to failure. Thus, numerical failure was assumed when the stress at the circumference of the area of the slab within the loading stub (or column) had reached its maximum compressive circumferential stress (or equivalent compressive plastic circumferential strain). This was found to occur after local yielding of the reinforcement in that region. This assumption was found to give accurate and consistent predictions and also agrees with experimental observations. Smaller slabs, which had a smaller area of slab outside the support lines, exhibited a shallower compression depth, while larger panels, which had a larger area of slab outside the support lines, had a relatively deeper compression zone around the concentrated load. This behaviour is analogous to that of lightly and heavily reinforced slabs.

\subsection{Ultimate Behaviour}

Figure 6 shows the distribution of stresses through the depth at mid-span, at 4 different loading stages, for one of Taylor's [14] specimens, S1, which was typical for all the one-way and two-way spanning slabs investigated. At an 
early stage of loading these distributions demonstrate an elastic behaviour with top and bottom stresses, i.e. compressive and tensile stresses, being almost equal. However, near ultimate these distributions demonstrate a plastic behaviour where the slab is cracked and compressive stresses close to the maximum value arise.

However, Taylor's Specimen S12 had exceptional conditions compared with all other restrained Taylor specimens. Interestingly, it was found that slab S12, which was loaded at $1 / 4$ span and reported by Taylor to fail by a combination of compression and shear failure at $500 \mathrm{kN}$, exhibited numerically unstable behaviour at a load of approximately $504 \mathrm{kN}$. Unfortunately, the three-dimensional shell elements used to simulate these slabs cannot be physically visualised through the depth using ABAQUS viewer module, but only graphical representation, as would be the case when conducting an analysis using solid/brick elements. This represents a limitation in the use of the three-dimensional shell elements. Thus, in order to examine what caused this instability, a two-dimensional plane stress analysis through the depth using brick elements was conducted. The contours of stresses through the depth at around similar load at which instabilities seemed to occur (i.e. $504 \mathrm{kN}$ ) are presented in Figure 7.

This figure clearly shows the development of a shear crack. Thus, numerical failure of this slab strip (S12) was assumed when this crack developed, although crushing of the concrete did not fully develop.

\section{ABAQUS Non-Linear Implicit and Explicit Analyses}

The explicit dynamic analysis is a dynamic procedure that performs a large number of small time increments efficiently. An explicit central-difference time integration rule is used; each time increment is relatively inexpensive when compared to standard implicit procedures because there is no solution of a set of simultaneous equations required at every increment. In other words, the use of small increments, dictated by a stability limit, is advantageous because it allows the solution to proceed without iterations and without requiring tangent stiffness matrices to be formed. It also simplifies the treatment of surface contacts. In fact, this analysis is based upon the implementation of an explicit integration rule together with the use of diagonal element mass matrices. The explicit central-difference operator satisfies the dynamic equilibrium equations at the beginning of each increment, at which the equations of motion for the body are integrated $[18,19]$.

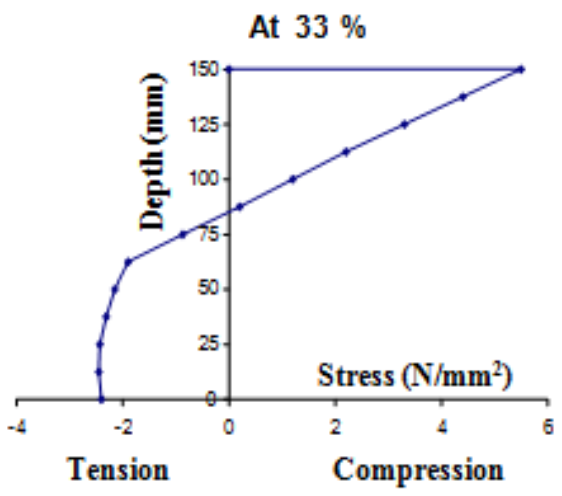

At $66 \%$

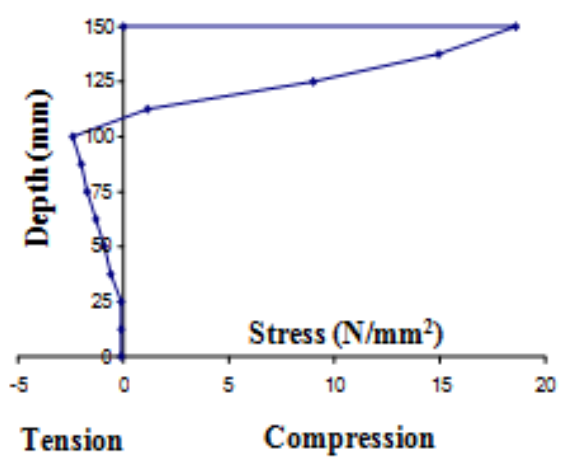

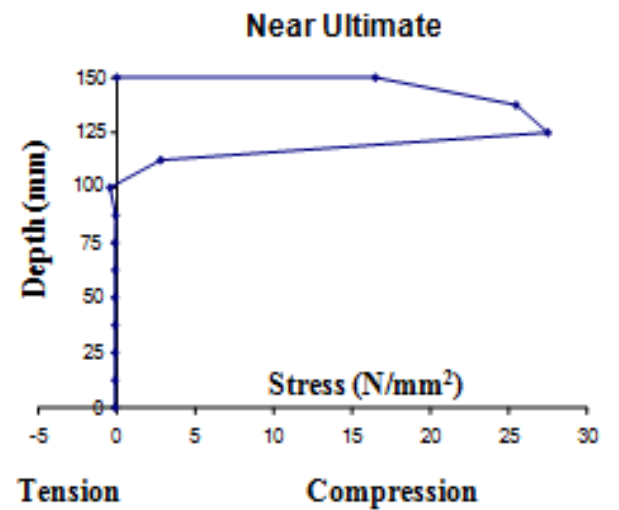

Figure 6. Distribution of stresses through the depth at mid-span at different loading percentages of ultimate for Taylor's [14] Specimen S1 


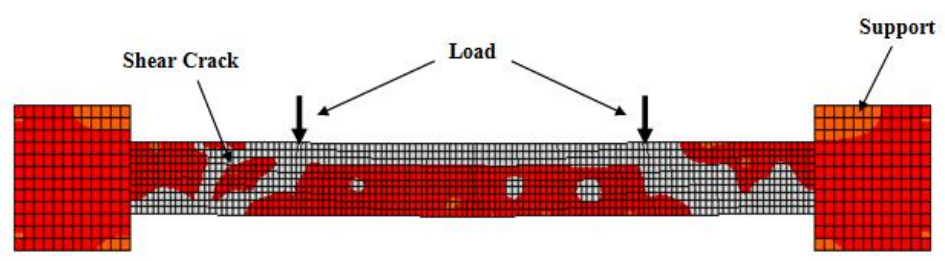

- Shear crack is shown at one end only because of tolerances in the numerical analysis.

Figure 7. Shear failure of Taylor's [14] Specimen S12 (Stress versus Load)

In spite of this analysis being dynamic, its advantages can be employed in the analysis of slower (quasi-static) processes. However, the output of an explicit analysis is not checked for accuracy as in the standard implicit (static) analysis which needs to satisfy a set of equilibrium static equations at each increment before proceeding to the next.

Although there was an initial convergence problem associated with the implicit analysis due to extensive non-linearity, implicit analysis was eventually used instead of the explicit dynamic analysis. The reasons for this decision were that the results obtained from the explicit analysis were not numerically checked for accuracy by the software and more specifically the difficulty of specifying an explicit dynamic analysis time period for load application that would satisfy static behaviour with no or minimum inertia effects yet maintaining consistent and accurate predictions. It was found that a small difference in time period (seconds) results in a big difference in the prediction of ultimate capacities and this was therefore seen to be an unmanageable approach for the authors.

\subsection{Non-Linear Implicit Static Analysis}

ABAQUS [5] offers two methods of non-linear implicit static analyses, as described below:

\subsubsection{Riks Method}

This method can provide solutions even in cases of complex, unstable response. In geometrically non-linear analyses, buckling or collapse can occur. In these cases a Riks static solution can be obtained, if the magnitude of the load does not have to follow a prescribed history; i.e. it must be part of the solution. This method can be used when the loading can be considered proportional (the loading over the complete structure can be scaled with a single parameter). It automatically adds or even removes load from the structure in different proportions at increments depending on whether or not the structure can take more or less loading.

In other unstable analyses where the instabilities are local, for example, material instability, or local buckling/collapse, the global load control methods, such as the Riks method are not generally appropriate $[18,19]$. Nevertheless, ABAQUS offers another broader analysis technique known as general static analysis which can be used to model most of the instability in structures.

\subsubsection{General Static Method}

This type of analysis is normally used in conjunction with a stabilising factor (dissipated energy fraction) which is used to apply damping throughout the model in a way that the viscous forces introduced are sufficiently large to prevent instantaneous buckling or collapse but small enough not to affect the static behaviour significantly while the problem is stable. The damping factor is chosen, based on extrapolation of the results obtained during the first increment, in conjunction with a dissipated energy fraction which is controlled by the user and has a default value of 2.0E-4. Although this value is small, it is very important, since it avoids difficulties with the convergence process. However, to be safe, a smaller value of $1 \mathrm{E}-5$ was used instead of the default value. Using smaller values than this seemed to cause great convergence difficulties for the investigated slab specimens. On the other hand slightly bigger values (such as 5E-5) did not have a significant effect on the results. This method provided the solution within a shorter time period than the Riks method.

Based upon these findings, the implicit general static analysis method was decided by the authors to be used for the modelling of all concrete slab specimens referred to in this investigation. This does not imply that the Riks method is not suitable for this purpose.

\subsection{Comparison between Riks Method and General Static Method}

The results of the ultimate load capacity predictions by the two methods for Taylor's [14] specimens are presented in Table 3. Zhing et al [27] had used the Riks method for the prediction of the enhanced ultimate strength of Taylor's slab specimens and was referred to in this comparison by $\left(\mathrm{P}_{\mathrm{FER}}\right)$. Both methods were found to provide very good predictions of the ultimate load capacities for Taylor's specimens. However, the applicability of the Riks method shall be tested on a wider range of specimens, as shown in this paper, including two-way spanning slab specimens.

Zhing et al [27] made slightly different assumptions regarding material properties. They assumed two different stress-strain relationships; one for concrete up to $60 \mathrm{~N} / \mathrm{mm}^{2}$ strength and the other one for greater than $60 \mathrm{~N} / \mathrm{mm}^{2}$. Additionally, in their plasticity model they assumed that the ratio of the initial equibiaxial compressive yield stress to initial uniaxial compressive yield stress was 1.1 instead of 1.0 assumed in this investigation for the one-way spanning slab strips of Taylor [14]. 


\section{Correlation with other Methods}

Tables 1 - 3 show the experimental $\left(\mathrm{P}_{\mathrm{T}}\right)$ and predicted ultimate loads of one-way slab strips reported in the literature (Roberts [16], Birke [17] and Taylor [14]) using conventional bending theory $\left(\mathrm{P}_{\mathrm{b}}\right)$, the CMA methodology developed at Queen's University Belfast $\left(\mathrm{P}_{\mathrm{Q}}\right)$ and the FEA model $\left(\mathrm{P}_{\mathrm{FEA}}\right)$. The methodology developed at Queen's University Belfast embodies Rankin and Long's [12] method for predicting the arching action strength enhancement in laterally restrained slab strips (used in Tables 1 and 2), Taylor's [14] development of the method for dealing with high strength concrete (used in Table 3) and Shaat's [15] development of the method to take into account the lateral restraint stiffness provided by the surrounding slab configuration in two-way slabs (used in Table 4).

Rankin and Long's [7] method for predicting the punching strength of conventional slab specimens was used for the punching analysis given in Table 5 . This method proposed a two phase approach for punching analysis; flexural punching and shear punching; which was mainly dependent on parameters such as span to depth ratio and reinforcement ratio. The difference between these two types of punching was that in flexural punching, the punching occurs after the development of considerable flexural deformation and cracking, which was observed experimentally.

The ratio of the maximum load supported by these specimens to that given by the conventional bending theory $\left(\mathrm{P}_{\mathrm{b}}\right)$, e.g. as described by Park and Paulay [23], for the one-way spanning slabs varied greatly depending on the concrete strength and the reinforcement percentage. The higher values of $\mathrm{P}_{\mathrm{T}} / \mathrm{P}_{\mathrm{b}}$ relate to slabs with lower levels of reinforcement and higher concrete strengths. This is considered to be due to the limitation of these conventional methods to allow for the effect of lateral restraint stiffness.

However the predictions of the non-linear FEA model were in good agreement with the experimental results of Roberts [16], Birke [17], Taylor [14] and Rankin [6] as shown in Tables $1-5$ (Average C.O.V for all specimens was $10 \%$ ). These tables also show similarly good correlation of test results with the predictions obtained from the CMA methodology developed at Queen's University Belfast (Average C.O.V for all specimens was also 10\%).

\section{Parametric Investigation}

The effect of various parameters on the ability of the FEA model and the Queen's University Belfast methodology to predict the ultimate capacities of slabs/beams was also investigated. These parameters include, compressive strength, reinforcement ratio, span to depth ratio, boundary conditions and lateral restraint stiffness. Both methods were able to predict the ultimate load capacities with a good accuracy and within a slight margin of conservatism as can be concluded from Tables $1-5$.

Figures $8-10$ show the effects of these various parameters on the FEA ultimate load predictions for all the specimens investigated in this paper by comparing the concrete strength, reinforcement percentage and span to depth ratio, to the ratios of test to predicted ultimate load capacities.

Except for a few tests, the FEA model predicted the slabs capacities conservatively and consistently considering the wide range of variables investigated in this study.

If all the investigated specimens were considered as a one group, the coefficient of variation of the ultimate capacity prediction ratio $\left(\mathrm{P}_{\mathrm{T}} / \mathrm{P}_{\mathrm{FEA}}\right)$ was found to be approximately $10 \%$.

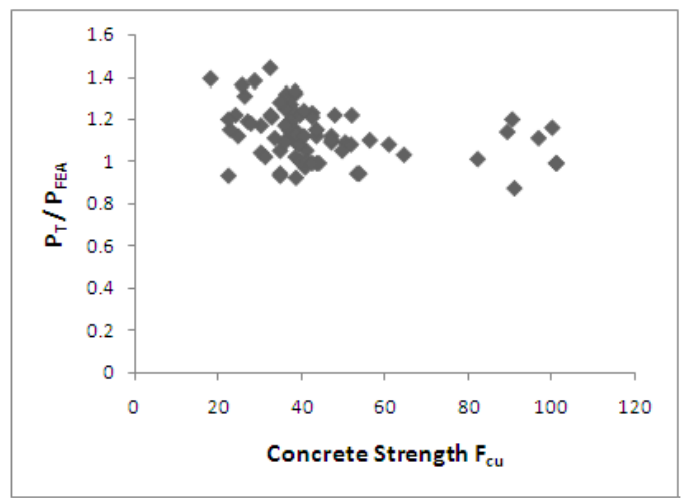

Figure 8. Correlation of the numerical predictions of the investigated specimens to concrete strength

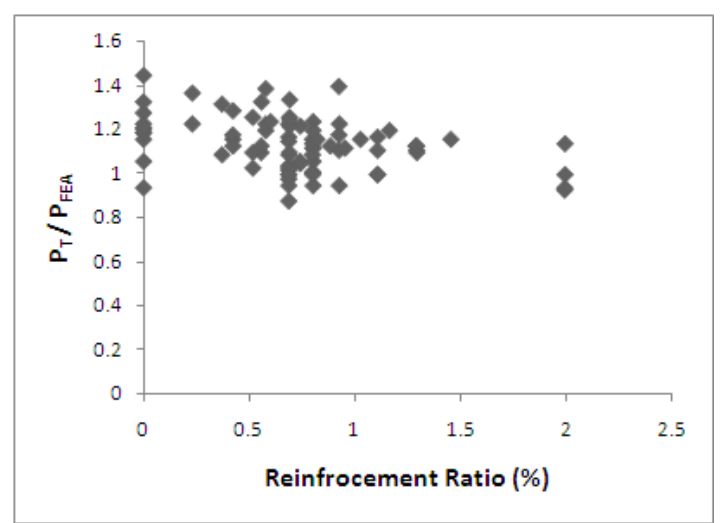

Figure 9. Correlation of the numerical predictions of the investigated specimens to reinforcement ratio

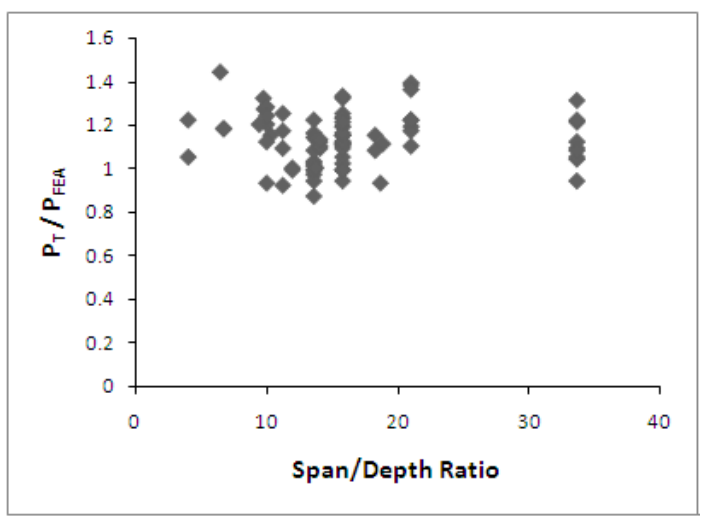

Figure 10. Correlation of the numerical predictions of the investigated specimens to span/depth ratio 


\section{Conclusions}

As a result of the numerical investigation presented in this paper, the following conclusions are drawn;

- $\quad$ The 4-node 3-D shell elements with six degrees of freedom were found to be adequate for the purpose of simulation. The behavior through the depth of these elements was calculated by solving numerical equations over a number of integration points. The use of these elements produced significant savings in computational time and cost compared to 3-D brick or solid continuum elements.

- Two types of analysis could be used for the purpose of the simulation; implicit static analysis or explicit dynamic analysis. However, the former was adopted due to difficulty in specifying an explicit dynamic analysis time period for load application that would satisfy static behaviour with no or minimum inertia effects yet maintaining consistent and accurate predictions. A small difference in the specified time period resulted in a significant difference in the simulation results and this was therefore seen by the authors to be an unmanageable approach.

- Two calculation methods could be used for the purpose of the simulation within the implicit static analysis; Riks method or general static method. However the later was used by the authors because Riks method required that the load does follow a prescribed history being part of the solution and more importantly was more difficult to manage in terms of convergence when compared to the general static method.

- The FEA numerical model developed was able to predict the ultimate load capacities of laterally restrained one-way and two-way reinforced and unreinforced concrete slabs having various configurations. Good consistent predictions for a wide range of variables i.e. concrete strength, slab depth, reinforcement ratio, boundary conditions and lateral restraint stiffness were obtained using the $3 \mathrm{D}$ Non-Linear FEA model of the ABAQUS Implicit General Static Method.

- The ultimate load capacities predicted using the compressive membrane action (CMA) methodology developed at Queen's University Belfast showed good correlation (that is acceptable in practice) to the FEA numerical method predictions, which suggests that the CMA methodology developed at Queen's University Belfast is correct.

- The use of FEA models shall be further investigated to achieve even more accurate and consistent predictions of ultimate behavior before being recommended for use in actual practice, as modeling by FEA requires much less time and cost than experimental test arrangements.

\section{Notation}

\author{
E Young's Modulus \\ A Cross-sectional area \\ k Lateral Restraint stiffness \\ $\Delta \quad$ Lateral expansion \\ $\mathrm{f}_{\mathrm{c}}$, Maximum compressive stress (based on cylinder \\ strength) \\ $\mathrm{f}_{\mathrm{cu}} \quad$ Cube compressive strength \\ $\mathrm{f}_{\mathrm{t}}$, Maximum tensile strength \\ h Slab thickness \\ $\rho \quad$ Reinforcement ratio \\ $\mathrm{P}_{\mathrm{T}} \quad$ Experimental failure load \\ $\mathrm{P}_{\mathrm{b}} \quad$ Predicted load capacity (given by the conventional \\ bending theory) \\ $\mathrm{P}_{\mathrm{Q}} \quad$ Predicted load capacity (given by the methods \\ developed at Queen's University Belfast) \\ $\mathrm{P}_{\mathrm{FEA}} \quad$ Predicted load capacity (given by the FE implicit \\ method) \\ $\mathrm{P}_{\mathrm{FER}} \quad$ Predicted load capacity (given by the FE implicit \\ Riks method)
}

\section{REFERENCES}

[1] Ockleston, A.J., 'Load tests on a three-storey reinforced concrete building in Johannesburg', The Structural Engineer, Vol. 33, Oct. (1955), pp $304-322$.

[2] Ockleston, A.J., 'Arching action in reinforced concrete slabs', The Structural Engineer, Vol. 36, Oct. (1958), pp $197-201$.

[3] Park, R. and Gamble, P., 'Reinforced concrete slabs', John Wiley and Sons, London, (1980), pp 562-612.

[4] Shaat, A., Cleland, D., Rankin, B. and Taylor, S., 'Compressive membrane action in reinforced concrete slabs' in the Proceedings of the 2003 Concrete Research in Ireland Colloquium, eds. P. A. M. Basheer and M. I. Russell, (2003), pp 53-58.

[5] Hibbitt, Karlsson and Sorenson, Inc., ABAQUS FEA suite of software - version 6.4, Warrington, Cheshire, United Kingdom (2002a).

[6] Rankin, G.I.B., 'Punching failure and compressive membrane action in reinforced concrete slabs', PhD Thesis, Dept of Civil Engineering, Queen's University of Belfast, (1982), 334 pp.

[7] Rankin, G.I.B. and Long, A.E., Predicting punching strength of conventional slab-column specimens, ICE Proceedings -Structures and Buildings, No.82, April (1987), pp 327-346.

[8] Rankin, G.I.B. and Long, A.E., Predicting the enhanced punching strength of interior slab-column connections, ICE Proceedings -Structures and Buildings, No.82, Dec. (1987), pp 1165-1186.

[9] Kirkpatrick, J., Rankin, G.I.B. and Long, A.E., 'Strength evaluation of M-beam bridge deck slabs', The Structural Engineer, Vol. 62B, No 3, Sept. (1984), pp 60-68. 
[10] Kirkpatrick, J., Rankin, G.I.B. and Long, A.E., 'The influence of compressive membrane action on the serviceability of beam and slab bridge decks', The Structural Engineer, Vol. 64B, No 1, March (1986), pp 6-9 and 12.

[11] Long, A. E., Kirkpatrick, J. and Rankin, G. I. B., Enhancing influences of compressive membrane action in bridge decks, Bridge Modification Conference Proceedings, (1995), Ch. 21, pp 217-227.

[12] Rankin, G. I. B. and Long, A. E., Arching action strength enhancement in laterally restrained slab strips, ICE Proceedings - Structures and Buildings, No. 122, Nov. (1997), pp 461-467.

[13] Highways Agency, 'Use of compressive membrane action in bridge decks', Design Manual for Roads and Bridges, Vol. 3, Section 4, Part 20, BD 81/02 (2002).

[14] Taylor S. E., Rankin G. I. B. and Cleland D. J., Arching action in high strength concrete slabs, ICE Proceedings - Structures and Buildings, No. 146, Nov. (2001), pp 353-362.

[15] Shaat, A., The Real Strength of Laterally Restrained Reinforced concrete Slabs, PhD thesis, Queen's University of Belfast (2005).

[16] Roberts, E.H., Load carrying capacity of slab strips restrained against longitudinal expansion, Concrete, Vol.3, No.9, Sep. (1969), pp 369-378.

[17] Birke, H., Kupoleffekt vid Betongplattor', Report No. 108, Institutionen for Byggnadsstatik, Royal Technical University, Stockholm, Sweden (1975).

[18] Hibbitt, Karlsson and Sorenson, Inc., ABAQUS FEA Theory Manual version 6.4, Warrington, Cheshire, United Kingdom (2002b).
[19] Hibbitt, Karlsson and Sorenson, Inc., ABAQUS FEA Analysis Manual version 6.4, Warrington, Cheshire, United Kingdom (2002c).

[20] Desayi, P. and Krishnan S., 'Equation for the stress-strain curve of concrete', J. Amer. Concr. Inst., 61, March (1964), pp 345-350.

[21] Neville, A, Properties of concrete, Fourth Edition, London (1995).

[22] Mattock, A.H. , Kriz, L.B. and Hognestad, E., 'Rectangular concrete stress distribution in ultimate strength design', Proceeding of the ACI, Vol.57, No. 8, Feb. (1961), pp 875-928.

[23] Park, R. and Pauley, T., 'Reinforced concrete structures', John Wiley and Sons Inc, Canada (1975).

[24] Scott, R.H. Technical Note 372, 'The short-term moment-curvature relationship for reinforced concrete beams', Proceedings of the Institution of Civil Engineers, Vol. 75, Part 2, Dec. (1983), pp 725-734.

[25] Guo Z.-H. and Zhang X.-Q., Investigation of complete stress-deformation curves for concrete in tension, ACI Materials Journal, 84, No.4, (1987), pp. 278-85.

[26] Masterson, D.M. and Long, A.E., The punching strength of slabs - a flexural approach using finite elements, ACI Special publication SP-42; Shear in reinforced concrete, V.2, Part 4, ACI, (1974), pp 747-768.

[27] Zheng, Y., Robinson, D., Taylor, S., Cleland, D. and Shaat, A., 'Analysis of compressive membrane action in concrete slabs', Proceedings of the ICE - Bridge Engineering, Volume 161, Issue 1, March (2008), pp $21-31$. 